\title{
Screening for left ventricular hypertrophy in patients with type 2 diabetes mellitus in the community
}

Jithendra B Somaratne, Gillian A Whalley, Katrina K Poppe, Mariska M ter Bals, Gina Wadams, Ann Pearl, Warwick Bagg and Rob N Doughty

\begin{abstract}
Background: Left ventricular hypertrophy $(\mathrm{LVH})$ is a strong predictor of cardiovascular disease and is common among patients with type 2 diabetes. However, no systematic screening for LVH is currently recommended for patients with type 2 diabetes. The purpose of this study was to determine whether NT-proBNP was superior to 12-lead electrocardiography (ECG) for detection of LVH in patients with type 2 diabetes.

Methods: Prospective cross-sectional study comparing diagnostic accuracy of ECG and NT-proBNP for the detection of LVH among patients with type 2 diabetes. Inclusion criteria included having been diagnosed for $>5$ years and/or on treatment for type 2 diabetes; patients with Stage 3/4 chronic kidney disease and known cardiovascular disease were excluded. ECG LVH was defined as either the Sokolow-Lyon or Cornell voltage criteria. NT-proBNP level was measured using the Roche Diagnostics Elecsys assay. Left ventricular mass was assessed from echocardiography. Receiver operating characteristic curve analysis was carried out and area under the curve (AUC) was calculated.
\end{abstract}

Results: 294 patients with type 2 diabetes were recruited, mean age 58 (SD 11) years, BP 134/81 \pm 18/11 mmHg, $\mathrm{HbA}_{1 \mathrm{c}} 7.3 \pm 1.5 \%$. LVH was present in 164 patients (56\%). In a logistic regression model age, gender, BMI and a history of hypertension were important determinants of LVH $(p<0.05)$. Only 5 patients with LVH were detected by either ECG voltage criteria. The AUC for NT-proBNP in detecting LVH was 0.68.

Conclusions: LVH was highly prevalent in asymptomatic patients with type 2 diabetes. ECG was an inadequate test to identify LVH and while NT-proBNP was superior to ECG it remained unsuitable for detecting LVH. Thus, there remains a need for a screening tool to detect LVH in primary care patients with type 2 diabetes to enhance risk stratification and management.

\section{Background}

The complications of type 2 diabetes are common and largely account for the excess morbidity and mortality associated with this disease. As such routine screening of asymptomatic patients with type 2 diabetes for retinopathy, nephropathy and neuropathy is recommended [1]. Diabetes is a major risk factor for coronary heart disease and cardiovascular disease is the most important cause of morbidity and mortality in patients with type 2

\footnotetext{
* Correspondence: r.doughty@auckland.ac.nz Cardiovascular Research Group, Department of Medicine, Faculty of Medical and Health Sciences, The University of Auckland, Private Bag 92019, Auckland Mail Centre, Auckland 1142, New Zealand
}

diabetes, accounting for approximately two-thirds of total mortality [2]. In addition, type 2 diabetes mellitus is associated with a cardiomyopathy characterised by left ventricular hypertrophy $(\mathrm{LVH})$ and diastolic dysfunction [3]. However, current guidelines do not recommend routine screening for structural heart disease in these patients [1].

Diabetes is associated with $\mathrm{LVH}$, left ventricular (LV) diastolic dysfunction [4,5], LV systolic dysfunction and cardiac autonomic neuropathy [3]. A large proportion of patients with type 2 diabetes and no known cardiovascular disease have LVH [6]. LVH is an important risk factor for cardiovascular disease in the general population

\section{() Biomed Central}

(c) 2011 Somaratne et al; licensee BioMed Central Ltd. This is an Open Access article distributed under the terms of the Creative Commons Attribution License (http://creativecommons.org/licenses/by/2.0), which permits unrestricted use, distribution, and reproduction in any medium, provided the original work is properly cited. 
[7]. Regression of LVH by pharmacological intervention is associated with an improvement in prognosis $[8,9]$. Therefore detection of $\mathrm{LVH}$ is attractive given the high prevalence and hence high pre-test probability of $\mathrm{LVH}$ in patients with type 2 diabetes.

In clinical practice the most reliable tool for quantifying left ventricular mass and diagnosing $\mathrm{LVH}$ is transthoracic echocardiography. Conversely the electrocardiogram (ECG), though inexpensive and widely available, is of limited use in detecting $\mathrm{LVH}$ in patients with type 2 diabetes due to its low sensitivity [10]. As both ECG and echocardiographic tools are currently unsuitable for wide population screening, there is a need for an accessible, acceptable, and economical test for detecting $\mathrm{LVH}$ in such patients. Identification of patients with $\mathrm{LVH}$ would facilitate the commencement of therapies that reduce LV mass and hence improve outcome. A biomarker, such as Nterminal pro brain natriuretic peptide (NT-proBNP), may be the solution. This simple and relatively inexpensive test can be measured from a non-fasting venous blood sample. NT-proBNP is released from the heart under conditions of increased wall stress [11] and is used primarily in the diagnosis of heart failure in patients with dyspnoea. Amongst patients with type 2 diabetes, higher BNP levels were observed in those with LVH [12].

Recent data suggests that NT-proBNP may be of value in identification of LVH among patients with hypertension presenting to emergency departments [13]. However, to date there have been no studies comparing diagnostic accuracy between NT-proBNP and ECG for detection of $\mathrm{LVH}$ in patients with type 2 diabetes. This study aimed to determine the value of NT-proBNP in the detection of $\mathrm{LVH}$ among patients with type 2 diabetes and no known cardiovascular disease in primary care.

\section{Methods}

In this investigator-initiated study, all researchers were independent of the funding bodies and had complete access to all data. Ethics approval was obtained from the Northern Y Regional Ethics Committee (New Zealand).

During a 14-month period (March 2006 - May 2007), 294 patients with type 2 diabetes diagnosed by their general practitioner, of at least 5 years duration and/or on treatment for type 2 diabetes, were prospectively recruited from primary care. Patients with known cardiac disease (including coronary heart disease, heart failure, LVH (identified on previous ECG or echo done for clinical purposes), moderate and severe valvular heart disease, atrial fibrillation), cerebrovascular disease (prior stroke or transient ischaemic attack), peripheral arterial disease, Stage 3 chronic kidney disease (eGFR $<60 \mathrm{~mL} / \mathrm{min}$ ) or inability to provide informed consent were excluded. A general practitioner (GP) network previously developed in the Natriuretic Peptides in the Community study [14] was used to facilitate recruitment of primary care patients. Patients meeting study inclusion and exclusion criteria were identified and referred to the study centre by 51 participating GPs within the Auckland region. Study personnel contacted referred patients, provided further details regarding the study and invited them to a study visit.

All patients were seen and evaluated in the Cardiovascular Research Clinic at The University of Auckland. During the study visit patient eligibility was confirmed and informed consent was obtained. Basic demographics and medical history including information regarding known microvascular complications of type 2 diabetes were recorded. The mean of three seated blood pressure (BP) measurements, separated by a minimum interval of five minutes, was obtained. Height, body mass, waist circumference, hip circumference, and body composition were measured. Blood was collected using standard venepuncture technique and samples were sent to a tertiary referral medical laboratory for measurement of creatinine, glucose, $\mathrm{HbA}_{1 \mathrm{c}}$, lipids, and NT-proBNP. A single urinary albumin:creatinine ratio measured within 12 months of the study visit was obtained from community laboratories. If this was unavailable, participants were directed to have this done soon after the study visit.

All patients had a resting transthoracic echocardiogram (Philips HDI 5000/iE33, Bothell, Seattle, Washington) which was the reference standard for the detection of $\mathrm{LVH}$ in this study performed by a research-trained sonographer. LV mass was assessed from M-mode images in accordance with The American Society of Echocardiography (ASE) guidelines [15]. When M-mode images were unsuitable for measurement, 2-dimensional images were used. The LV mass gender-specific cut-offs for LVH used were: $>45 \mathrm{~g} / \mathrm{m}^{2.7}$ in women and $>49 \mathrm{~g} /$ $\mathrm{m}^{2.7}$ in men[15]. All echocardiographic measurements were made by a cardiologist with subspecialty training in echocardiography. For LV mass the coefficient of variability for intra-observed repeated measures is less than $8 \%$ [16]. The echocardiographer and cardiologist measuring the images were blinded to ECG and NTproBNP results.

All patients had a standard unfiltered 12-lead ECG (Philips Hewlett-Packard PageWriter 200 Cardiograph, Andover, Massachusetts). Each ECG was measured by a single analyst using a $150 \mathrm{~mm}$ digital vernier calliper under a five-fold magnification. ECG criteria used for the detection of $\mathrm{LVH}$ included the Sokolow-Lyon $\left(\mathrm{SV}_{1}+\right.$ $\mathrm{RV}_{5 / 6}$ )[17] and Cornell (women $\mathrm{RaVL}+\mathrm{SV}_{3}+0.8 \mathrm{mV}$; men $\mathrm{RaVL}+\mathrm{SV}_{3}$ )[18] voltage criteria. Standard cutoffs for the electrocardiographic diagnosis of $\mathrm{LVH}$ were used: Sokolow-Lyon voltage $>3.5 \mathrm{mV}$ [17] and 
Cornell voltage $>2.8 \mathrm{mV}[18]$. Patients meeting either criterion were considered to have LVH by ECG. The ECG analyst was blinded to echocardiographic and NT-proBNP results. Thirty participants were randomly selected for estimation of test reproducibility. This analysis demonstrated an intra-observer and interobserver variability of $\leq 0.01 \mathrm{mV}$ for measurement of ECG voltages.

NT-proBNP levels were measured using the Roche Diagnostics Elecsys assay (pmol/L). The performance characteristics claimed by the manufacturer are an analytical sensitivity of $0.6 \mathrm{pmol} / \mathrm{L}$ and functional sensitivity of $<5.9 \mathrm{pmol} / \mathrm{L}$.

\section{Statistical methods}

In the Casale Monferrato Study [19] the prevalence of ECG LVH was $17 \%$. Assuming $90 \%$ power approximately 200 patients with diabetes and no LVH and 50 patients with diabetes with LVH would resolve an area under a Receiver Operating Characteristic (ROC) curve (AUC) of 0.8 and 0.9 between ECG LVH and NTproBNP. To allow for information not being available from all patients the sample size was 300 subjects.

Normally distributed variables are presented as mean (standard deviation) and significantly skewed variables as median (interquartile range). Receiver operating characteristic (ROC) curve analyses were performed to evaluate the diagnostic performance of NT-proBNP in the detection of $\mathrm{LVH}$, with sub-analyses on the basis of age, gender, BMI and albuminuria. The area under the curve (AUC) was used to assess the discriminative ability of NT-proBNP. Sensitivity, specificity, predictive values and the positive likelihood ratio are calculated at the threshold determined by the maximal Youden index.

Multivariable logistic regression was used to investigate the relationship between patient factors and LVH. Variables were selected for inclusion in the model on the basis of biological plausibility. The natural logarithm of NT-proBNP was used to satisfy model assumptions.

Analyses were performed using SAS 9.1 (SAS Institute Inc, Cary, NC, USA) statistical software.

\section{Results}

Of the 365 potential participants referred by 51 general practitioners, 60 were ineligible, uncontactable or did not attend their study visit (Figure 1). A further 11 participants were excluded due to permanent atrial fibrillation, Stage 3 chronic kidney disease, known LVH, previous stroke or failing to satisfy inclusion criteria. The remaining 294 participants were included in the study. The mean age of participants was $58 \pm 11$ years, $49 \%$ were women, $42 \%$ were Caucasian, $33 \%$ were Polynesian (Mäori and Pacific Islander) and 25\% were Asian. Mean body mass index $(\mathrm{BMI})$ was $31.9 \pm 7.0 \mathrm{~kg} / \mathrm{m}^{2}$ and mean
BP 134/81 $\pm 18 / 11 \mathrm{mmHg}$. Median time since diagnosis of type 2 diabetes was 6 years (range 1 month - 50 years). Mean $\mathrm{HbA}_{1 \mathrm{c}} 7.3 \pm \mathrm{SD} 1.5 \%$ and median urinary albumin: creatinine ratio (UACR) was 1.2 (IQR $0.4,4.0) \mathrm{mg} / \mathrm{mmol}$. One hundred and eighty nine (66\%) participants had a normal UACR (<2.5 mg/mmol), 72 (25\%) had microalbuminuria (UACR $2.5-20 \mathrm{mg} / \mathrm{mmol}$ ) and 27 (9\%) had macroalbuminuria (UACR $>20 \mathrm{mg} / \mathrm{mmol}$ ). A history of known retinopathy was noted in $14 \%$, nephropathy in $11 \%$ and neuropathy in $8 \%$. Many participants had a history of other cardiovascular risk factors such as hypertension (60\%) and dyslipidaemia (70\%). Half of all participants were prescribed aspirin, $61 \%$ a statin and $47 \%$ an angiotensin converting enzyme (ACE) inhibitor. Nearly all patients were on pharmacological therapy for type 2 diabetes (94\%): 244 were on oral hypoglycaemic therapy alone, 6 on subcutaneous insulin therapy alone and 25 on both. Of the 269 participants on oral hypoglycaemic therapy, 243 (90\%) were on metformin, 130 (48\%) on a sulphonylurea, 8 (3\%) on a thiazolidinedione and 1 on acarbose. (See Table 1)

The mean LV mass index was $51.5 \pm 14.6 \mathrm{~g} / \mathrm{m}^{2.7}$. LVH was diagnosed by echocardiography in 164 of the 294 participants (56\%). Using the ASE partition values of LV mass index [15], 52 participants (18\%) had mild LVH (women $45-51 \mathrm{~g} / \mathrm{m}^{2.7}$, men $49-55 \mathrm{~g} / \mathrm{m}^{2.7}$ ), 49 (17\%) moderate LVH (women $52-58 \mathrm{~g} / \mathrm{m}^{2.7}$, men $56-63 \mathrm{~g} / \mathrm{m}^{2.7}$ ) and $63\left(21 \%\right.$ ) severe LVH (women $\geq 59 \mathrm{~g} / \mathrm{m}^{2.7}$, men $\geq 64 \mathrm{~g} / \mathrm{m}^{2.7}$ ). Of the 119 participants with no previous history of hypertension, 44 (37\%) had LVH. Participants on either an ACE inhibitor or angiotensin receptor blocker were more likely to have LVH (62\% vs. 49\%). The European Society of Hypertension (ESH) and European Society of Cardiology (ESC) 2007 Guidelines for the Management of Arterial Hypertension use LV mass index thresholds of $110 \mathrm{~g} / \mathrm{m}^{2}$ for women and $125 \mathrm{~g} / \mathrm{m}^{2}$ for men to diagnose LVH [20]. By this more conservative definition, 79 (27\%) had LVH. (See Table 1)

Important incidental findings on echocardiography included a resting regional wall motion abnormality in 17 (6\%) and LV systolic dysfunction in 12 (4\%). LV diastolic dysfunction, as assessed by mitral filling pattern, demonstrated abnormal relaxation in 173 (59\%) and pseudonormal filling in 87 (30\%) of patients. (See Table 1)

\section{Detection of left ventricular hypertrophy}

Only 4 of the 164 participants (2\%) with known echocardiographic LVH were correctly detected by either the Sokolow-Lyon or Cornell voltage criteria. The sensitivity of ECG for detecting echocardiographic LVH was 2\% (95\% CI 1 to 6\%) with a specificity of $99 \%$ (95\% CI 96 to $100 \%)$.

The median NT-proBNP level was $6.0 \mathrm{pmol} / \mathrm{L}$ (range of $<0.6-175.0$ ). The area under the curve (AUC) for NT-proBNP in discriminating patients with LVH from 


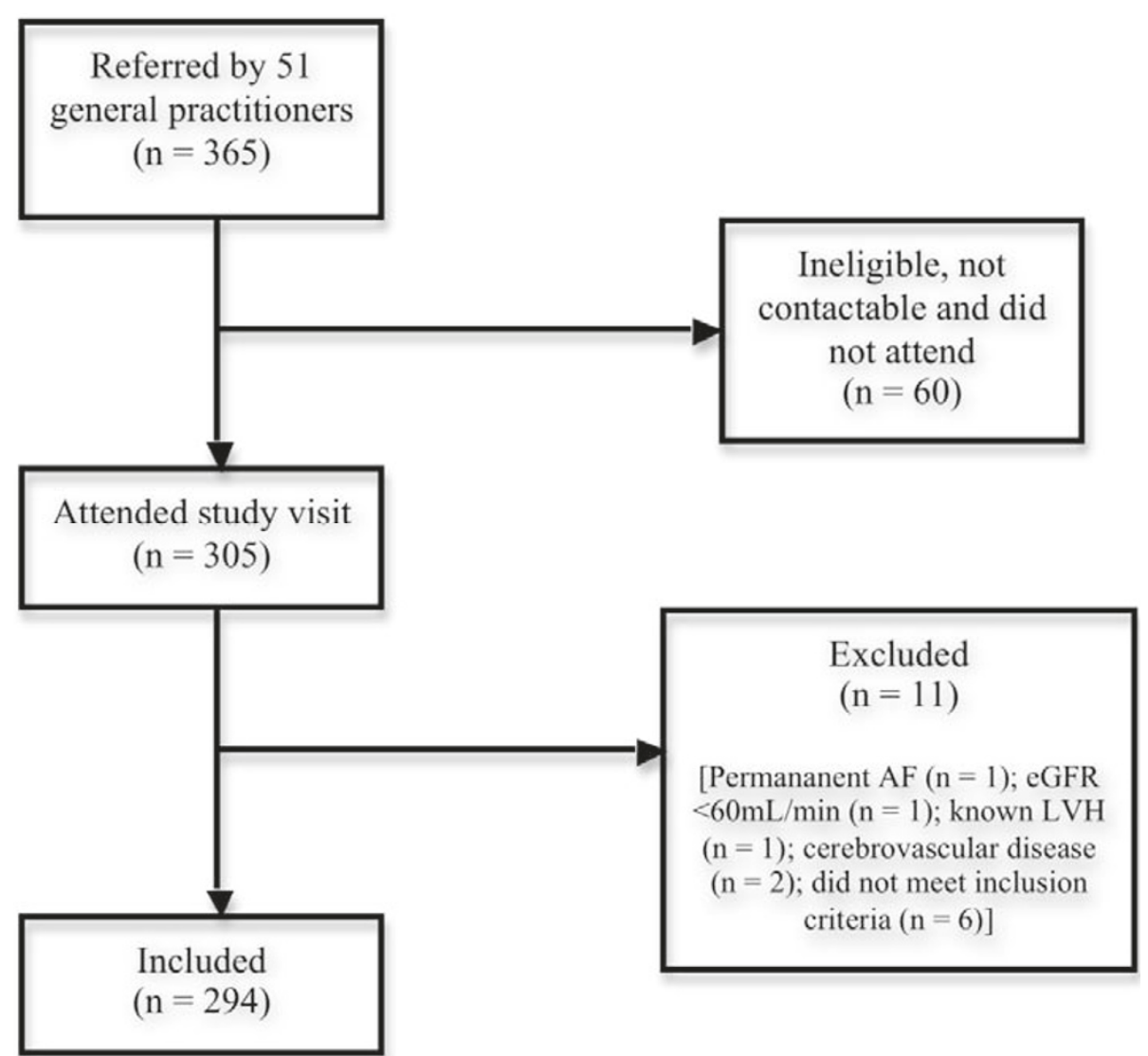

Figure 1 Participant flow. Abbreviations: AF atrial fibrillation, eGFR estimated glomerular filtration rate, LVH left ventricular hypertrophy

those with no LVH was 0.68 (95\% CI 0.62 to 0.74 ) (Figure 2). The maximum Youden index was established at an NT-proBNP level of $4.4 \mathrm{pmol} / \mathrm{L}(37.3 \mathrm{pg} / \mathrm{mL})$. At this cut off the sensitivity was $68 \%$ (95\% CI 60 to $75 \%$ ) and the specificity was $58 \%$ (95\% CI 50 to $68 \%$ ). There was no improvement in the performance of NT-proBNP in distinguishing between patients with moderate-severe LVH and those with no LVH-mild LVH (AUC 0.64). Similarly, using the ESH/ESC definition of LVH, there was no difference in the utility of NT-proBNP in identifying patients with LVH (AUC 0.64). When participants were categorised into three groups [normal UACR $(<2.5$ $\mathrm{mg} / \mathrm{mmol}$ ), microalbuminuria (UACR $2.5-20.0 \mathrm{mg} /$ $\mathrm{mmol}$ ) and macroalbuminuria (UACR $>20 \mathrm{mg} / \mathrm{mmol}$ )] the median NT-proBNP level was similar: 6.0 (IQR 3.0 12.0) $\mathrm{pmol} / \mathrm{L}, 6.0$ (IQR 3.0-16.5) $\mathrm{pmol} / \mathrm{L}$ and 8.0 (IQR $3.0-21.0) \mathrm{pmol} / \mathrm{L}$ respectively.

There was some variability in the diagnostic accuracy of NT-proBNP between subgroups of participants (Figure 2). For example, the AUC was higher in women (0.72 vs. 0.61) and in those with a BMI below the median of $30.8 \mathrm{~kg} / \mathrm{m}^{2}$ (0.78 vs. 0.56$)$. There was no difference in AUC for patients with UACR $\geq 2.5 \mathrm{mg} / \mathrm{mmol}(0.68)$ and $<2.5 \mathrm{mg} / \mathrm{mmol}$ (0.69).
In a multivariable model including age, gender, history of hypertension, time since diagnosis of type 2 diabetes, $\mathrm{BMI}, \mathrm{HbA}_{1 \mathrm{c}}$, the presence of albuminuria, and $\log _{\mathrm{e}}(\mathrm{NT}-$ proBNP), the significant determinants of $\mathrm{LVH}$ were: BMI $\left(\chi^{2} 24.7 ;<0.001\right)$, age $\left(\chi^{2} 8.3 ; \mathrm{p}=0.004\right)$, history of hypertension $\left(\chi^{2} 4.9 ; \mathrm{p}=0.028\right)$, and gender $\left(\chi^{2} 4.1 ; \mathrm{p}=0.043\right)$.

\section{Discussion}

This study, involving a group of patients with type 2 diabetes with no known cardiac, cerebrovascular or peripheral vascular disease, has demonstrated that LVH (defined according to the ASE guidelines [15]) was common, occurring among $56 \%$ of the patients. The detection of LVH by standard ECG criteria was poor and while NT-proBNP was superior to ECG in discriminating $\mathrm{LVH}$, it remains unsuitable for use as a screening tool due to inadequate optimum sensitivity and specificity.

\section{Clinical importance of left ventricular hypertrophy}

The prevalence of $\mathrm{LVH}$ in patients with type 2 diabetes has varied considerably based on the mode of detection and baseline characteristics of the cohort studied. The high proportion (56\%) of participants with $\mathrm{LVH}$ in this 


\section{Table 1 Patient characteristics}

\begin{tabular}{|c|c|}
\hline \multicolumn{2}{|l|}{ Clinical } \\
\hline Female, $\mathrm{n}$ & $145(49 \%)$ \\
\hline Age, years $(S D)$ & $58(11)$ \\
\hline Median duration of diabetes, months (IQR) & $72(36,120)$ \\
\hline History of hypertension, $n$ & $175(60 \%)$ \\
\hline History of dyslipidaemia, n & $206(70 \%)$ \\
\hline Body mass index, kg/m² (SD) & $31.9(7.0)$ \\
\hline Systolic blood pressure, mmHg (SD) & $134(18)$ \\
\hline Diastolic blood pressure, mmHg (SD) & $81(11)$ \\
\hline $\mathrm{HbA}_{1 \mathrm{c}} \%$ (SD) & $7.3(1.5)$ \\
\hline Median UACR, mg/mmol (IQR) & $1.2(0.4,4.0)$ \\
\hline Normal UACR (<2.5 mg/mmol), $\mathrm{n}$ & $189(66 \%)$ \\
\hline Microalbuminuria (UACR $2.5-20 \mathrm{mg} / \mathrm{mmol}$ ), $\mathrm{n}$ & $72(25 \%)$ \\
\hline Macroalbuminuria (UACR $\geq 20 \mathrm{mg} / \mathrm{mmol}$ ), $\mathrm{n}$ & $27(9 \%)$ \\
\hline \multicolumn{2}{|l|}{ Current therapy } \\
\hline Oral hypoglycaemic therapy, $\mathrm{n}$ & $269(91 \%)$ \\
\hline Subcutaneous insulin therapy, $\mathrm{n}$ & $31(11 \%)$ \\
\hline Any antihypertensive therapy, $\mathrm{n}$ & $190(65 \%)$ \\
\hline Statin therapy, $\mathrm{n}$ & $178(61 \%)$ \\
\hline \multicolumn{2}{|l|}{ Echocardiographic characteristics } \\
\hline Left ventricular mass, g (SD) & $207(63)$ \\
\hline Left ventricular mass index, $\mathrm{g} / \mathrm{m}^{2.7}$ (SD) & $51.5(14.6)$ \\
\hline Left ventricular hypertrophy, n & $164(56 \%)$ \\
\hline Mild, $\mathrm{n}$ & $52(18 \%)$ \\
\hline Moderate, $n$ & $49(17 \%)$ \\
\hline Severe, $n$ & $63(21 \%)$ \\
\hline Regional wall motion abnormality, $\mathrm{n}$ & $17(6 \%)$ \\
\hline Left ventricular systolic dysfunction, $n$ & $12(4 \%)$ \\
\hline Left ventricular diastolic dysfunction, $\mathrm{n}$ & $260(89 \%)$ \\
\hline Abnormal relaxation, $\mathrm{n}$ & $173(59 \%)$ \\
\hline Pseudonormal filling, $\mathrm{n}$ & 87 (30\%) \\
\hline
\end{tabular}

Values represent mean unless stated. Abbreviations: $I Q R$ interquartile range, $S D$ standard deviation, UACR urinary albumin:creatinine ratio.

study is comparable with previously reported data. For example, echocardiographic LVH was found in 22\% [12] and $51 \%$ [21] of Australian diabetes clinic attendees. A higher prevalence of echocardiographic LVH (71\%) was noted in diabetes clinic attendees in Dundee, Scotland [22], although a lower proportion (9.4\%) among patients with diabetes without known macrovascular complications in a recent study from Sweden [4]. In our study $37 \%$ of participants with no history of hypertension had $\mathrm{LVH}$; suggesting that type 2 diabetes per se is associated with LVH. More importantly the clinically prevalent combination of type 2 diabetes and hypertension was strongly linked to the development of $\mathrm{LVH}$, occurring in $69 \%$ of such patients.

The relationship between LVH and poor prognosis [7] would suggest that this common finding in patients with type 2 diabetes is clinically significant. For example in the Reduction of End Points in Non-insulin Dependent
Diabetes Mellitus with the Angiotensin II Antagonist Losartan (RENAAL trial), LVH was associated with an increased risk of death, end-stage renal disease and doubling of serum creatinine (hazard ratio 1.41; p $<0.001$ ) in patients with type 2 diabetes, clinical nephropathy and no known cardiovascular disease [23].

$\mathrm{LVH}$ is emerging as an important independent therapeutic target. Treatment with losartan was associated with a reduction in ECG LVH in the RENAAL trial [23]. A change in $\mathrm{LVH}$ voltage criteria was an independent predictor of cardiovascular events in hypertensive patients with diabetes in the Appropriate Blood Pressure Control in Diabetes (ABCD) trial [24]. These data provide some hope that, in asymptomatic patients with type 2 diabetes, the aggressive treatment of LVH per se or risk factors for $\mathrm{LVH}$, such as hypertension, may yield significant long term prognostic benefits. A substudy of the Losartan Intervention For Endpoint Reduction in Hypertension (LIFE) study focussing on patients with diabetes suggested that patients with diabetes experienced less regression of $\mathrm{LVH}$ in response to losartan and any regression was not predictive of future cardiovascular events [25]. The increased formation of advanced glycation end products and their cross-linking with myocardial collagen associated with diabetes was proposed as a mechanism to account for this difference. This highlights the need to develop other therapies specifically targeting $\mathrm{LVH}$, independent of BP lowering, such as advanced glycation end product-protein breakers [26].

\section{Detection of left ventricular hypertrophy \\ ECG}

The 12-lead ECG, the most commonly used tool for diagnosis of LVH in the community, performed poorly in detecting LVH compared to echocardiography. The most widely used ECG criteria are the Sokolow-Lyon voltage criteria. Using these criteria, the prevalence of $\mathrm{LVH}$ in this cohort would only be $1 \%$. The combination of both the Sokolow-Lyon and the Cornell voltage criteria only raised the prevalence to $1.7 \%$. Similarly in the Scottish study of diabetes clinic patients, in whom the prevalence of echocardiographic LVH was $71 \%$, the prevalence of ECG LVH using the LIFE criteria was only 9.2\% [22]. The poor performance of ECG in detecting $\mathrm{LVH}$, using voltage-based criteria, may result from the attenuation of electrocardiographic voltages at the skin surface by increased fat mass in obese individuals [27]. In our study participants with a higher BMI were found to have a higher prevalence of echocardiographic $\mathrm{LVH}$ (73\% vs. 39\%), yet lower mean Sokolow-Lyon voltages $(1.7 \mathrm{mV}$ vs. $1.9 \mathrm{mV})$ and the same mean Cornell voltages $(1.2 \mathrm{mV})$. 
A

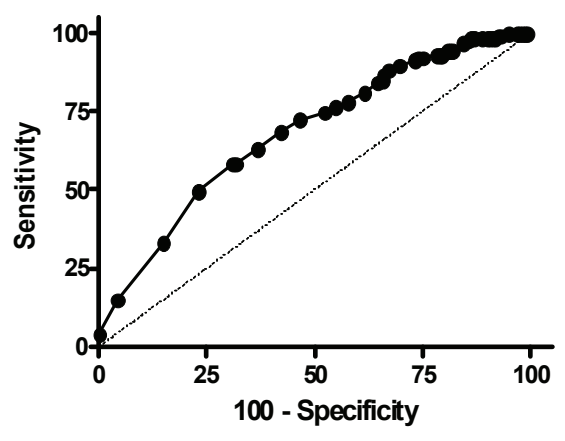

$\mathrm{B}$
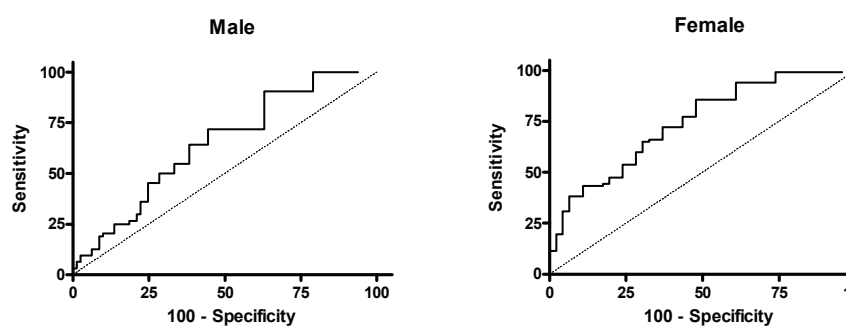

C

Low BMI

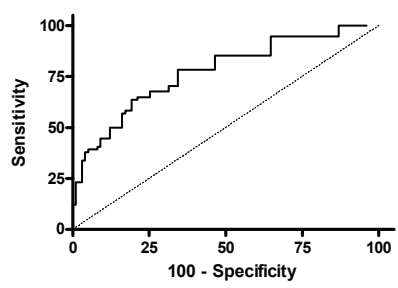

High BMI

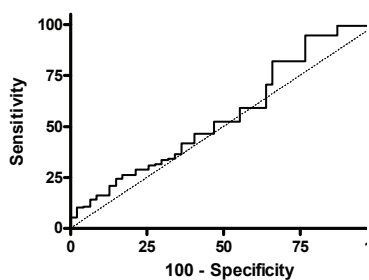

$\mathrm{D}$
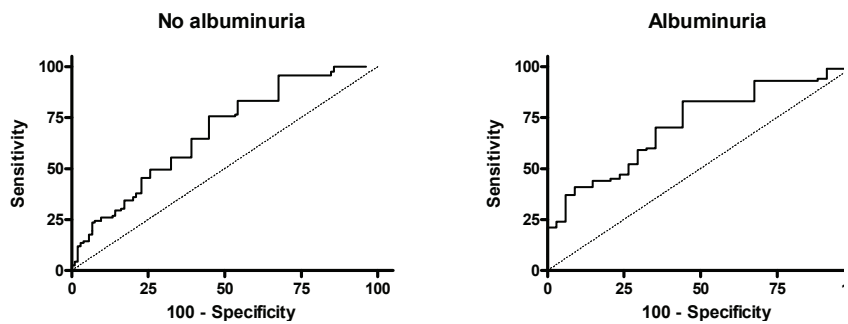

Figure 2 Receiver operating characteristic curves for NT-proBNP in discriminating left ventricular hypertrophy for whole group (A) and according to: gender (B); body mass index (BMI, C); presence of albuminuria (urinary albumin:creatinine ratio $\geq 2.5 \mathrm{mg} / \mathrm{mmol}, \mathrm{D}$ )

\section{NT-proBNP}

Though NT-proBNP was far superior to ECG in detecting $\mathrm{LVH}$ it was inadequate for general use as a screening tool for LVH in community patients with type 2 diabetes and no overt cardiovascular disease. One possible explanation for the poor performance of NT-
proBNP in detecting $\mathrm{LVH}$ in this study relates to the low levels of NT-proBNP levels (median $6.0 \mathrm{pmol} / \mathrm{L}$ ) in comparison to diagnostic cut-offs for heart failure [14]. This may relate to the both the obese nature of this cohort (mean BMI $31.9 \mathrm{~kg} / \mathrm{m} 2$ ) as well as the prevalence of metabolic risk factors. Metabolic risk factors have 
previously been independently associated with lower natriuretic peptide levels [28]. Thus the release of NTproBNP promoted by $\mathrm{LVH}$ in our patients may well have been dampened by the counterinfluence of obesity and metabolic risk factors. Recently data has suggested that a combined approach using ECG and NT-proBNP can improve identification of $\mathrm{LVH}$ among patients with hypertension presenting to emergency departments [13]. However, this study was from a small number of patients (49) among whom $43 \%$ had LVH from the ECG and while promising these results would need to be confirmed in a larger study and this approach has not been evaluated among patients with diabetes.

The functional sensitivity, the lowest concentration that can be reliably measured with a between-run coefficient variation of $20 \%$, of the NT-proBNP assay $(<5.9$ $\mathrm{pmol} / \mathrm{L}$ ) employed in this study may have significantly decreased the performance of NT-proBNP in detecting LVH. Approximately half of this cohort had a NTproBNP measurement below the functional sensitivity. The imprecise nature of the assay at these low concentrations may conceal the true relationship between LVH and NT-proBNP level in this cohort. The optimal statistical NT-proBNP cut-off for the detection of LVH (4.4 $\mathrm{pmol} / \mathrm{L}$ using the maximum Youden index) is not clinically useful as it well below the functional sensitivity of the available assay.

\section{Future approaches}

Given the poor performance of current ECG LVH criteria and NT-proBNP in detecting echocardiographic $\mathrm{LVH}$ there is a need for the development of alternative methods for detecting this prevalent complication which is associated with an adverse prognosis. The main limitation of current voltage-based ECG LVH criteria appears to be the attenuation of electrocardiographic voltages at the skin surface by subcutaneous fat. Indexing voltages to measures of body composition, such as body fat percentage, may help adjust for the attenuation of voltages by increased body fat and increase the utility of current voltage criteria in obese individuals. At present the Framingham-adjusted Cornell voltage criteria is the only available ECG LVH criteria adjusting for a measure of body size by incorporating BMI [29]. Other voltage-independent ECG LVH, such as QRS duration and QT interval, require further investigation this population.

Another possible tool for the detection of LVH in the community is hand-carried echocardiography (HCE). This is a cheaper, user-friendly and more accessible alternative to standard transthoracic echocardiography. A limited echocardiographic study using HCE may be a valuable screening tool for not just LVH but also resting regional wall motion abnormalities, significant LV systolic and diastolic dysfunction in a group of asymptomatic individuals at high risk of cardiovascular disease. This would require further prospective evaluation.

\section{Limitations}

Systematic assessment for silent myocardial ischaemia was not assessed in this study and hence its confounding influence is uncertain. Chronic stable coronary heart disease is known to be associated with higher natriuretic peptide levels[30]. Though patients with known coronary heart disease were excluded from our study we did not assess or exclude patients with silent myocardial ischaemia. While silent myocardial ischaemia may have been a confounding factor we believe that it has not significantly altered the overall results or conclusions of this study given the low NT-proBNP levels observed.

The quality of ECG recordings is important for accurate detection of LVH. In this study all ECG recordings were performed by staff that were trained and supervised by a registered technologist and using a state-ofthe-art machine. Furthermore, all measurements were performed by a single observer according to protocol and quality reviewed by a cardiologist. Lastly, it is possible that the failure to detect LVH was related to the over-estimation of LVH by echocardiography. This is unlikely since the echoes were performed according to a strict protocol and reviewed and measured by a trained echocardiologist, and the prevalence of LVH is similar to other published cohorts.

\section{Conclusion}

In conclusion, LVH was highly prevalent in asymptomatic patients with type 2 diabetes. ECG was an inadequate test to identify $\mathrm{LVH}$ in these patients. NTproBNP though superior to ECG remains unsuitable as a screening tool to detect $\mathrm{LVH}$ in patients with type 2 diabetes. There remains a need for a screening tool to detect LVH in patients with type 2 diabetes in primary care to enhance risk stratification and management.

\section{Acknowledgements}

The study was supported by a Project Grant from the New Zealand National Heart Foundation. Dr Jithendra Somaratne was supported by the Douglas Goodfellow Medical Research Fellowship by the Auckland Medical Research Foundation and the Greenlane Research and Educational Fund. Dr Gillian Whalley was the National Heart Foundation of New Zealand Senior Fellow. Ms Katina Poppe is the recipient of a postgraduate scholarship from the National Heart Foundation of New Zealand.

We acknowledge the following general practitioners based in the Auckland region who helped with patient recruitment to this study: Dr F Abeysekera, Dr T Akroyd, Dr J Carnachan, Dr J Carter, Dr R Chan, Dr S Chand, Dr G Collinson, Dr T Croker, Dr D de Lacey, Dr H Doerr, Dr L Gabriel, Dr H Gardyne, Dr S George, Dr D Good, Dr M Goodey, Dr N Hefford, Dr K Jayavant, Dr H Jenkins, Dr A Kandelaki, Dr S Kara, Dr M Long, Dr M Lowe, Dr P McArthur, Dr N Matti, Dr M Ng, Dr J O'Sullivan, Dr N Patel, Dr A Sharma, Dr Y Sinnathamby, Dr R Stewart, Dr R Stirling, Dr M Stone, Dr J Tseung, Dr A Twhigg, Dr S Weeramuni, Dr C Wong, and Dr P Woolford. 


\section{Authors' contributions}

RND and GAW conceived of the study. JBS, AP, RND, MMterB, WB and GW were responsible for study design and acquisition of data. GAW and RND performed and analysed the echocardiograms. KKP undertook the statistical analysis. JBS drafted first version of the manuscript. All authors have been involved in drafting and revision of the manuscript for important intellectual content and have read and approved the final manuscript for publication.

\section{Competing interests}

The authors declare that they have no competing interests.

Received: 29 November 2010 Accepted: 14 April 2011

Published: 14 April 2011

\section{References}

1. American Diabetes Association: Standards of Medical Care in Diabetes 2007. Diabetes Care 2007, 30(suppl_1):S4-41.

2. Adult Treatment Panel III: Third Report of the National Cholesterol Education Program (NCEP) Expert Panel on Detection, Evaluation, and Treatment of High Blood Cholesterol in Adults (Adult Treatment Panel III) Final Report. Circulation 2002, 106(25):3143.

3. Fang ZY, Prins JB, Marwick TH: Diabetic cardiomyopathy: evidence, mechanisms, and therapeutic implications. Endocrine Reviews 2004. 25(4):543-567.

4. Magnusson M, Jovinge S, Shahgaldi K, Israelsson B, Groop L, Melander O: Brain natriuretic peptide is related to diastolic dysfunction whereas urinary albumin excretion rate is related to left ventricular mass in asymptomatic type 2 diabetes patients. Cardiovascular Diabetology 2010, 9(1):2.

5. Romano S, Di Mauro M, Fratini S, Guarracini L, Guarracini F, Poccia G, Penco M: Early diagnosis of left ventricular diastolic dysfunction in diabetic patients: a possible role for natriuretic peptides. Cardiovascular Diabetology 2010, 9(1):89.

6. Palmieri V, Tracy RP, Roman MJ, Liu JE, Best LG, Bella JN, Robbins DC, Howard BV, Devereux RB, Strong Heart S: Relation of left ventricular hypertrophy to inflammation and albuminuria in adults with type 2 diabetes: the Strong Heart Study. Diabetes Care 2003, 26(10):2764-2769.

7. Kannel WB, Gordon T, Castelli WP, Margolis JR: Electrocardiographic Left Ventricular Hypertrophy and Risk of Coronary Heart Disease. Annals of Internal Medicine 1970, 72(6):813-822.

8. Verdecchia P, Angeli F, Borgioni C, Gattobigio R, de Simone G, Devereux RB, Porcellati C: Changes in cardiovascular risk by reduction of left ventricular mass in hypertension: a meta-analysis. American Journal of Hypertension 2003, 16(11 Pt 1):895-899.

9. Devereux RB, Wachtell K, Gerdts E, Boman K, Nieminen MS, Papademetriou V, Rokkedal J, Harris K, Aurup P, Dahlöf B: Prognostic significance of left ventricular mass change during treatment of hypertension. JAMA 2004, 292(19):2350-2356.

10. Dawson A, Rana BS, Pringle SD, Donnelly LA, Morris AD, Struthers AD: How much echo left ventricular hypertrophy would be missed in diabetics by applying the Losartan Intervention For Endpoint Reduction electrocardiogram criteria to select patients for angiotensin receptor blockade? Journal of Hypertension 2004, 22(7):1403-1408.

11. Maeder MT, Mariani JA, Kaye DM: Hemodynamic Determinants of Myocardial B-Type Natriuretic Peptide Release: Relative Contributions of Systolic and Diastolic Wall Stress. Hypertension 2010, 56(4):682-689.

12. Fang ZY, Schull-Meade R, Leano R, Mottram PM, Prins JB, Marwick TH: Screening for heart disease in diabetic subjects. American Heart Journal 2005, 149(2):349-354

13. Limkakeng AT Jr, Drake W, Mani G, Freeman D, Best R, Newby LK, Chandra A: Left ventricular dysfunction screening in hypertensive patients with $\mathrm{N}$-terminal pro-B-type natriuretic peptide and electrocardiogram. The American Journal of Emergency Medicine 2010, Corrected Proof.

14. Wright SP, Doughty RN, Pearl A, Gamble GD, Whalley GA, Walsh HJ, Gordon G, Bagg W, Oxenham H, Yandle T, et al: Plasma amino-terminal pro-brain natriuretic peptide and accuracy of heart-failure diagnosis in primary care: a randomized, controlled trial. Journal of the American College of Cardiology 2003, 42(10):1793-1800.

15. Lang RM, Bierig M, Devereux RB, Flachskampf FA, Foster E, Pellikka PA, Picard MH, Roman MJ, Seward J, Shanewise JS, et al: Recommendations for chamber quantification: a report from the American Society of Echocardiography's Guidelines and Standards Committee and the Chamber Quantification Writing Group, developed in conjunction with the European Association of Echocardiography, a branch of the European Society of Cardiology. Journal of the American Society of Echocardiography 2005, 18(12):1440-1463.

16. Whalley GA, Gamble GD, Doughty RN, MacMahon S, Sharpe N: Selection bias in clinical research when subjects are excluded because of failure to estimate left ventricular mass by echocardiography. J Am Soc Echocardiogr 1998, 11:1050-1055.

17. Sokolow M, Lyon TP: The ventricular complex in left ventricular hypertrophy as obtained by unipolar precordial and limb leads. American Heart Journal 1949, 37(2):161-186.

18. Casale PN, Devereux RB, Kligfield P, Eisenberg RR, Miller DH, Chaudhary BS, Phillips MC: Electrocardiographic detection of left ventricular hypertrophy: development and prospective validation of improved criteria. Journal of the American College of Cardiology 1985, 6(3):572-580.

19. Bruno G, Giunti S, Bargero G, Ferrero S, Pagano G, Perin PC: Sex-differences in prevalence of electrocardiographic left ventricular hypertrophy in Type 2 diabetes: The Casale Monferrato Study. Diabetic Medicine 2004, 21(8):823-828.

20. The Task Force for the Management of Arterial Hypertension of the European Society of Hypertension (ESH) and of the European Society of Cardiology (ESC): 2007 Guidelines for the management of arterial hypertension. Eur Heart J 2007, 28(12):1462-1536.

21. Srivastava PM, Calafiore P, Macisaac RJ, Patel SK, Thomas MC, Jerums G, Burrell LM: Prevalence and predictors of cardiac hypertrophy and dysfunction in patients with Type 2 diabetes. Clinical Science 2008, 114(4):313-320.

22. Dawson A, Morris AD, Struthers AD: The epidemiology of left ventricular hypertrophy in type 2 diabetes mellitus. Diabetologia 2005, 48(10):1971-1979.

23. Brenner BM, Cooper ME, de Zeeuw D, Keane WF, Mitch WE, Parving HH, Remuzzi G, Snapinn SM, Zhang Z, Shahinfar S, et al: Effects of Losartan on Renal and Cardiovascular Outcomes in Patients with Type 2 Diabetes and Nephropathy. N Engl J Med 2001, 345(12):861-869.

24. Havranek EP, Esler A, Estacio RO, Mehler PS, Schrier RW: Differential effects of antihypertensive agents on electrocardiographic voltage: results from the Appropriate Blood Pressure Control in Diabetes (ABCD) trial. American Heart Journal 2003, 145(6):993-998.

25. Okin PM, Devereux RB, Gerdts E, Snapinn SM, Harris KE, Jern S, Kjeldsen SE, Julius $S$, Edelman JM, Lindholm $L H$, et al: Impact of diabetes mellitus on regression of electrocardiographic left ventricular hypertrophy and the prediction of outcome during antihypertensive therapy: the Losartan Intervention For Endpoint (LIFE) Reduction in Hypertension Study. Circulation 2006, 113(12):1588-1596.

26. Liu J, Masurekar MR, Vatner DE, Jyothirmayi GN, Regan TJ, Vatner SF, Meggs LG, Malhotra A: Glycation end-product cross-link breaker reduces collagen and improves cardiac function in aging diabetic heart. American Journal of Physiology - Heart \& Circulatory Physiology 2003, 285(6): H2587-2591.

27. Levy D, Labib SB, Anderson KM, Christiansen JC, Kannel WB, Castelli WP: Determinants of sensitivity and specificity of electrocardiographic criteria for left ventricular hypertrophy. Circulation 1990, 81(3):815-820.

28. Wang TJ, Larson MG, Keyes MJ, Levy D, Benjamin EJ, Vasan RS: Association of Plasma Natriuretic Peptide Levels With Metabolic Risk Factors in Ambulatory Individuals. Circulation 2007, 115(11):1345-1353.

29. Norman JE Jr, Levy D, Campbell G, Bailey JJ: Improved detection of echocardiographic left ventricular hypertrophy using a new electrocardiographic algorithm. Journal of the American College of Cardiology 1993, 21(7):1680-1686.

30. Weber M, Dill T, Arnold R, Rau M, Ekinci O, Msller KD, Berkovitsch A, Mitrovic V, Hamm C: N-terminal B-type natriuretic peptide predicts extent of coronary artery disease and ischemia in patients with stable angina pectoris. American Heart Journal 2004, 148(4):612-620.

doi:10.1186/1475-2840-10-29

Cite this article as: Somaratne et al: Screening for left ventricular hypertrophy in patients with type 2 diabetes mellitus in the community. Cardiovascular Diabetology 2011 10:29. 